\title{
Destinação de pás de turbinas eólicas instaladas no Estado da Bahia, Brasil
}

\section{Mário Joel Ramos Júnior* e Edna dos Santos Almeida}

Centro Universitário Senai CIMATEC. Programa de Pós-Graduação em Gestão e Tecnologia Industrial. Avenida Orlando Gomes, 1845. Salvador-BA, Brasil. (CEP 41650-010). *E-mail: ramosjuniormariojoel@gmail.com.

Resumo. 0 Estado da Bahia ocupa o primeiro lugar em geração de energia eólica no Brasil. Em outubro de 2020, a Bahia tinha 177 parques eólicos em operação com capacidade instalada de 4.406 MW e geração de 1,95 TW/h. 0 crescimento da energia eólica na Bahia trouxe diversos benefícios, a exemplo de diversificação da matriz energética do estado, da segurança energética e da atração de investimentos, bem como desafios relacionados à destinação dos componentes, como as pás eólicas, após o período de vida útil. Estas pás das turbinas eólicas são construídas com materiais compósitos, tendo como base fibra de vidro ou fibra de carbono. Neste contexto, o objetivo deste trabalho é avaliar quais são as opções e os desafios para a destinação ambientalmente correta das pás eólicas utilizadas nos parques eólicos localizados na Bahia, após o final da vida útil. Em outros países, o descarte em aterros ou incineração em plantas de processamento de resíduos têm sido o tratamento mais comum para as pás eólicas das turbinas eólicas após o final da vida útil. Entretanto, foi identificado que a reciclagem de materiais compósitos é uma indústria em fase embrionária que pode beneficiar não somente a indústria eólica, mas também outras indústrias, tais como a automotiva. Através do desenvolvimento de pesquisa no estado, sugere-se que a Bahia tenha um centro de reciclagem de materiais compósitos que poderá atender a todo o país.

Palavras-chave: Pás eólicas; Reciclagem; Desmontagem; Resíduos; Descomissionamento.

Abstract. Destination of wind turbine blades installed in the State of Bahia, Brazil. The state of Bahia ranks first in wind energy generation in Brazil. In October 2020, Bahia had 177 wind farms in operation with an installed capacity of 4,406 MW and generation of $1.95 \mathrm{TW} / \mathrm{h}$. The growth of wind energy in Bahia brought several benefits such as diversification of the state's energy matrix, energy security and attraction of investments, as well as challenges related to the destination of components, such as wind turbine blades, after the useful life period. The blades of wind turbines are built with composite materials, based on fiberglass or carbon fiber. In this context, the objective of this
Recebido

23/04/2021

Aceito

26/07/2021

Disponível on line

$31 / 07 / 2021$

Publicado

31/08/2021

Acesso aberto

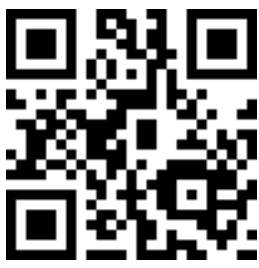

ORCIL

(1) 0000-0002-0420-7194 Mário Joel Ramos Júnior

(1) 0000-0001-5111-062X

Edna dos Santos

Almeida

ISSN 2359-1412/RBGAS-2021-0040/2021/8/19/24/979

Rev. Bras. Gest. Amb. Sustent. http://revista.ecogestaobrasil.net 
article is to evaluate what are the options and challenges for the correct destination of the wind blades used in the wind farms located in Bahia, after the end of life. Landfill disposal or incineration at waste processing plants has been the most common treatment for wind turbine blades after the end of their useful life worldwide. However, it was identified that the recycling of composite materials is an embryonic industry that can benefit not only for the wind industry, but also from others industries such as the automotive industry. Through the development of research in the state, it is suggested that Bahia may have a recycling center for composite materials that can serve the entire country.

Keywords: Wind turbine blade; Recycling; Disassembly; Waste; Decommisioning.

\section{Introdução}

Após a crise de energia de 2001 ("Apagão 2001"), o Brasil vem desenvolvendo políticas públicas para aumentar a participação da energia renovável na matriz elétrica nacional. De acordo com Cherrington et al. (2012), durante a operação, as turbinas eólicas produzem eletricidade a partir do vento; uma fonte abundante e renovável de energia.

A participação da energia renovável na matriz energética brasileira amentou de 41,3\% em 2015 para 46,2\% em 2019 (EPE, 2020). De acordo com ABEEÓLICA (2020), a capacidade eólica instalada no Brasil cresceu quase duas vezes entre 2015 e 2019, saindo de 8.723 MW para 15.449 MW e representando uma taxa média de crescimento de $15,36 \%$ ao ano. No ranking mundial de capacidade eólica acumulada, o Brasil ocupa a sétima posição, sendo o primeiro país da América do Sul (GWEC, 2020).

Duarte Júnior et al. (2021) ressaltaram que no Brasil os estados e os municípios podem elaborar políticas públicas com regulamentações voltadas à geração de energia elétrica, porém no caso dos governos estaduais e municipais, a tônica continua sendo a concessão de benefícios fiscais para geração e uso. A ABEEÓLICA (2020) indica que 86,7\% de toda a energia eólica gerada no Brasil em 2019 foi proveniente do Nordeste, com destaque para os Estados da Bahia, Rio Grande do Norte, Piauí e Ceará.

Em 2019, pela primeira vez na história, a Bahia ocupou o primeiro lugar em geração de energia eólica no Brasil. A taxa de crescimento da geração de energia eólica entre 2015 e 2019 foi de 43,13\% ao ano no estado. Conforme informado por SDE (2020), em outubro de 2020, a Bahia tinha 177 parques eólicos em operação com capacidade instalada de 4.406 MW e geração de 1,95 TW/h, o que é capaz de abastecer cerca de 16 milhões de residências e beneficiar cerca de 48 milhões de habitantes. Adicionalmente, existiam 54 parques em processo de construção e 78 com licença de construção aprovada. A previsão é que a capacidade instalada na Bahia seja de 8.193 MW até 2025. SDE (2020) também destaca que foram gerados mais de 66.000 empregos em toda cadeia produtiva, sendo mais de 48.400 empregos diretos na fase de construção dos parques que já estão em operação que existe a previsão de geração de 56.000 empregos diretos e indiretos para os parques que estão em construção e aqueles em construção ainda não iniciada.

O Atlas do Estado da Bahia lançado em 2013 (Camargo-Schubert, 2013) indica que o potencial de energia eólica na Bahia é estimado em $70 \mathrm{GW}$ (devido a ventos maiores que $7,0 \mathrm{~m} / \mathrm{s}$ a $100 \mathrm{~m}$ de altura), valor este muito superior à capacidade instalada até outubro de $2020(4,41 \mathrm{GW})$. Desta forma, se pode inferir que a indústria eólica está em pleno crescimento no estado. 
A Confederação Nacional das Indústrias (CNI, 2016) ressalta que o setor de energias renováveis está em franco crescimento na Bahia, consolidando-se como o principal polo nacional na fabricação de componentes para a cadeia produtiva de energia eólica do País. Já existem mais de 30 empresas atuando no setor eólico na Bahia, Acciona, GE Wind, Sany, Siemens, Vestas, WEG e Wobben Windpower (fabricantes de aerogeradores), Torrebras e TEM (fabricantes de torres eólicas), Tecis e Aeris (fabricantes de pás eólicas), entre outras empresas de engenharia, comissionamento, manutenção e outros componentes.

No Brasil, até 2030, mais de 50 parques alcançarão a faixa dos 20 anos de operação, representando mais de 600 aerogeradores e de 940 MW de potência (EPE, 2021). O Parque Eólico de Brotas de Macaúbas, inaugurado em 20 de setembro de 2012 na Chapada Diamantina, foi o primeiro empreendimento para geração eólica no estado. 0 Complexo Eólico é formado por 57 turbinas, distribuídas pelos municípios de Brotas de Macaúbas, Novo Horizonte e Seabra. Cada turbina tem a capacidade de 1,5 MW e diâmetro de rotor de $80 \mathrm{~m}$. 0 diâmetro das turbinas eólicas vem aumentando consideravelmente no decorrer dos últimos anos. A maior turbina eólica disponível comercialmente em 2016 tinha 8 MW de capacidade e rotor com diâmetro de 164 metros (IRENA, 2016). Atualmente, a empresa GE está desenvolvendo a turbina Haliade-X12MW com capacidade de 12 MW e rotor com diâmetro de 220 metros. À medida que a indústria eólica global cresce em número de turbinas e tamanho, o mesmo acontece com o fluxo de resíduos dos componentes a serem descartados após o final da vida útil.

0 crescimento da energia eólica na Bahia trouxe diversos benefícios: diversificação da matriz energética do estado, segurança energética, atração de investimentos, redução das perdas oriundas da transmissão de energia, geração de empregos e desenvolvimento de centros de pesquisa especializados, entre outros. Por outro lado, apesar da energia eólica produzir poucos resíduos durante a geração da eletricidade (quando comparado a outras fontes não renováveis), é preciso minimizar os possíveis impactos ambientais dos componentes, a exemplo das pás das turbinas eólicas, no final do ciclo de vida.

As pás das turbinas eólicas são construídas com materiais compósitos, tendo como base fibra de vidro ou fibra de carbono e têm uma vida útil estimada de 20-25 anos (Geiger et al., 2020). Tal característica faz com que o seu destino seja objeto de grande preocupação para o meio ambiente (EPE, 2021).

A pesquisa de Liu e Barlow (2017) indicou que haverá 43 milhões de toneladas de resíduos de pás eólicas em todo o mundo em 2050, com a China possuindo $40 \%$ dos resíduos, a Europa 25\%, os Estados Unidos $16 \%$ e o resto do mundo 19\%. Sultan et al. (2018) e Ratner et al. (2020) destacam que o descarte em aterros ou incineração em plantas de processamento de resíduos continuam sendo os tratamentos mais comuns das pás de turbinas eólicas após a vida útil.

Desta forma, o objetivo deste trabalho é avaliar quais são as opções e os desafios para a destinação ambientalmente correta das pás eólicas utilizadas nos parques eólicos localizados na Bahia, após o final da vida útil. Para tal, foi realizada uma revisão sistemática da literatura e avaliadas as opções a serem utilizadas na Bahia.

\section{Material e métodos}

Os critérios utilizados para a identificação e seleção dos estudos para compor esta revisão sistemática foram:

1) Elaboração das perguntas norteadoras:

a) Quais as opções para a destinação correta das pás utilizadas nos Parques Eólicos localizados na Bahia, após o final da vida útil?

b) Quais os desafios para a destinação ambientalmente adequada das Pás Eólicas? 
2) A seleção da plataforma eletrônica de periódicos acadêmicos das bases de dados utilizadas para a realização de buscas para esta revisão sistemática: a Science Direct e o Google Scholar.

3) A definição de descritores e combinações com busca de palavras-chave de acordo com a plataforma selecionada: "wind turbine blade" and "disassembly" and "waste or recycling". critérios:

4) A seleção primária dos artigos encontrados de acordo com os seguintes

a) Pertinência dos conteúdos em relação ao tema abordado neste trabalho;

b) Trabalhos nos idiomas inglês e português;

c) Trabalhos de pesquisa ou revisão da literatura;

d) Exclusão de teses e dissertações; e

e) Exclusão de patentes, citações e capítulos de livros.

5) Seleção secundária de trabalhos após leitura integral do artigo. Com a utilização dos descritores citados anteriormente, foram identificados 93 estudos, sendo 19 da Science Direct e 74 da Google Scholar. Após utilização dos critérios citados anteriormente, 13 trabalhos foram selecionados, sete da Science Direct e seis da Google Scholar. Após a leitura na íntegra, seis estudos foram excluídos por não responder às questões norteadoras e seis trabalhos foram selecionados como pertinentes para compor esta revisão sistemática.

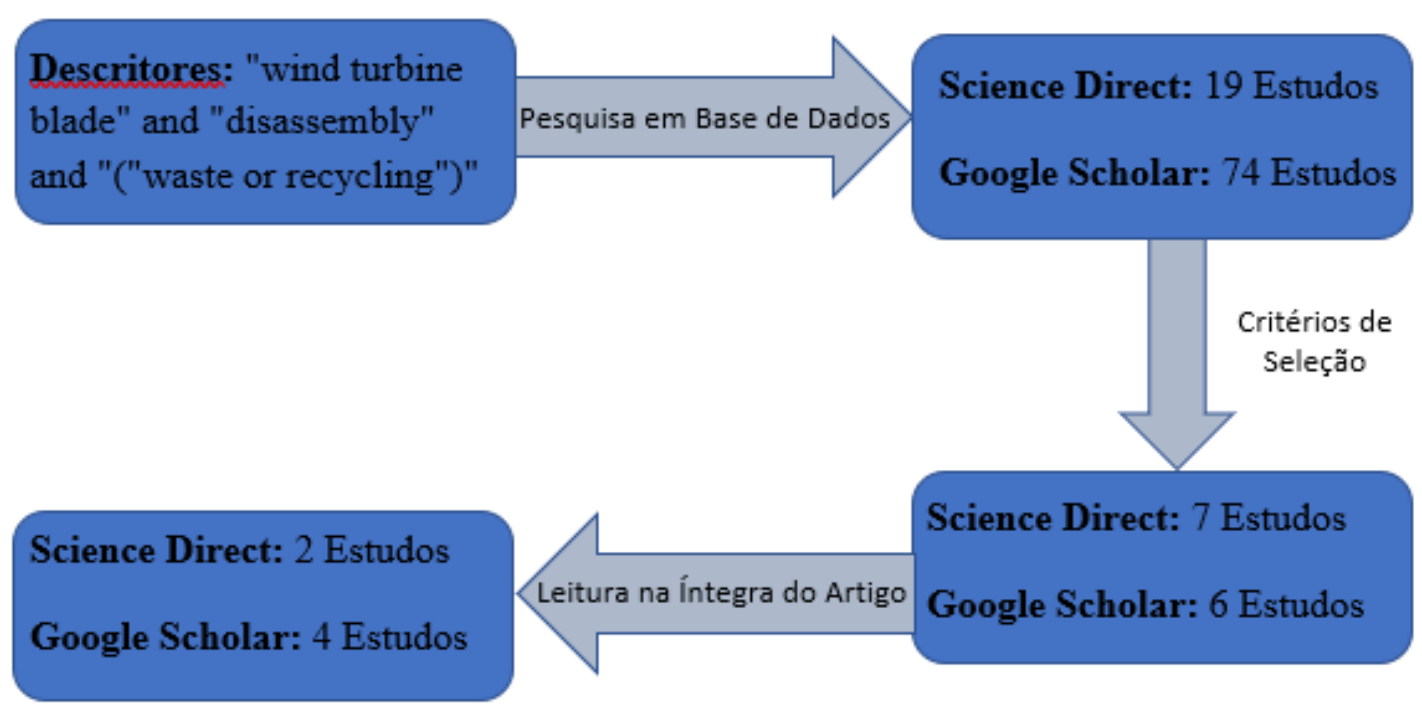

Figura 1. Seleção de artigos acadêmicos para compor a revisão sistemática.

Para avaliação das opções e desafios para a destinação correta das pás das turbinas eólicas na Bahia, será considerado nesta etapa que o Parque Eólico de Brotas de Macaúbas, primeiro parque eólico instalado na Bahia, em 2012, será o primeiro parque eólico a ser descomissionado no estado baiano.

Este parque eólico é composto por 57 turbinas (total de 171 pás eólicas) e está localizado a uma distância média de 600 quilômetros da cidade de Salvador (capital da Bahia). Será considerado que as características das pás eólicas são o comprimento de 
40 m, peso de 20 t e a vida útil de 20 anos. Portanto, em 2032, haverá um total de $3.240 \mathrm{t}$ de pás eólicas em desuso que necessitarão de um descarte ambientalmente correto.

\section{Resultados}

A Tabela 1 resume as opções e os desafios para a destinação correta das pás das turbinas eólicas, de acordo com a revisão sistemática da literatura.

Tabela 1. Resumo de opções e desafios para a destinação correta das pás das turbinas eólicas.

\begin{tabular}{|c|c|c|}
\hline Referência & Q1: Opções para a destinação & $\begin{array}{l}\text { Q2: Os desafios para a } \\
\text { destinação }\end{array}$ \\
\hline Larsen (2009) & $\begin{array}{l}\text { Aterros, incineração/recuperação } \\
\text { energética e reciclagem, visando ao } \\
\text { reforço de concreto, produtos } \\
\text { laminados, reforço de resina de } \\
\text { polipropileno reciclado, reforço de } \\
\text { fibra em enchimento, colas e pinturas, } \\
\text { peças termoplásticas, asfalto e } \\
\text { concreto. }\end{array}$ & $\begin{array}{l}\text { A falta de volume torna a } \\
\text { reciclagem financeiramente } \\
\text { difícil (economia de escala). }\end{array}$ \\
\hline Cherrington et al. (2012) & $\begin{array}{l}\text { Reciclagem mecânica, pirólise, } \\
\text { oxidação em leitos fluidizados e } \\
\text { reciclagem química. }\end{array}$ & $\begin{array}{l}\text { Desenvolvimento de mercado } \\
\text { consumidor para o material } \\
\text { compósito reciclado e } \\
\text { problemas de logísticas } \\
\text { relacionados à desmontagem, } \\
\text { transporte e corte. }\end{array}$ \\
\hline Sultan et al. (2018) & $\begin{array}{l}\text { Venda a mercados menos maduros, } \\
\text { reutilização inovadora: playgrounds e } \\
\text { centros artísticos infantis, reciclagem } \\
\text { do material compósito através dos } \\
\text { métodos biotecnológicos, químico, } \\
\text { eletroquímico, leito fluidizado, } \\
\text { fragmentação de alta tensão, } \\
\text { reciclagem mecânica ou pirólise }\end{array}$ & $\begin{array}{l}\text { Transporte para centros de } \\
\text { reciclagem. }\end{array}$ \\
\hline Akbar e Liew (2020) & Produção de cimento. & $\begin{array}{l}\text { Os autores não responderam } \\
\text { a essa pergunta. }\end{array}$ \\
\hline Ratner et al. (2020) & 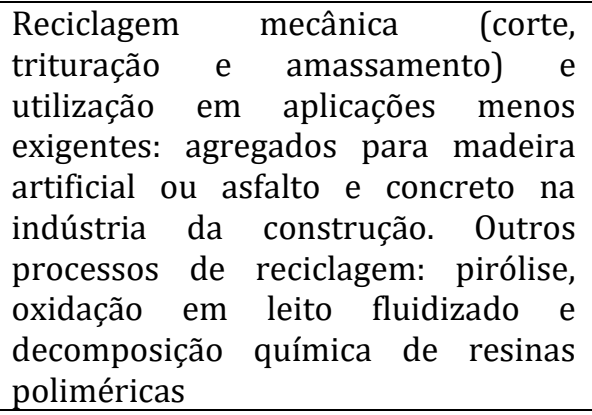 & \begin{tabular}{lrr} 
Viabilidade & \multicolumn{2}{r}{ econômica da } \\
reciclagem dos materiais \\
compósitos: & custo do \\
processo e tamanho do \\
mercado de materiais \\
reciclados.
\end{tabular} \\
\hline Geiger et al. (2020) & $\begin{array}{l}\text { Aterro, incineração e reciclagem; } \\
\text { Reformas para estender a vida útil ou } \\
\text { reutilização; Adaptação para } \\
\text { utilização em outros projetos: pontes, } \\
\text { playgrounds, pontos de ônibus, } \\
\text { assentos públicos, placas de } \\
\text { sinalização ou garagem para } \\
\text { bicicletas }\end{array}$ & $\begin{array}{l}\text { Reciclagem de materiais } \\
\text { compósitos em escala } \\
\text { industrial ainda e melhorar as } \\
\text { propriedades mecânicas do } \\
\text { material reciclado. }\end{array}$ \\
\hline
\end{tabular}




\section{Opções para a destinação das pás das turbinas eólicas}

Larsen (2009) informa que existem as rotas possíveis para as pás das turbinas eólicas desmontadas: aterro industrial (que está em processo de desuso em países europeus por se tratar de disposição, sem valorização como insumo para outro processo); incineração (sendo o calor da incineração utilizado para gerar eletricidade, bem como alimentar o sistema de aquecimento de um distrito) e reciclagem. Entretanto, no caso da incineração $60 \%$ da sucata é transformada em cinzas, podendo ocasionar danos à saúde e segurança de trabalhadores envolvidos no processamento em incineradores. Outra opção é a reciclagem visando a utilização em silos, reforço de concreto, produtos laminados, reforço de resina de polipropileno reciclado, reforço de fibra em enchimento, colas e pinturas, peças termoplásticas, asfalto e concreto.

Cherrington et al. (2012) citam que os métodos de reciclagem de matérias compósitos são a reciclagem mecânica, pirólise, oxidação em leitos fluidizados e reciclagem química. 0 método mais simples é o de reciclagem mecânica, no entanto, esse processo danifica as fibras individuais, reduzindo o desempenho mecânico. 0 material reciclado produzido é de baixo valor e não pode ser reutilizado em novas pás eólicas, sendo utilizado para aplicações menos exigentes, como o asfalto para a construção civil. Os autores concluíram que a reciclagem de circuito fechado promoveria a solução mais sustentável. Para tal, os fabricantes precisam desenvolver projetos de pás eólicas que sejam recicláveis para facilitar os métodos sustentáveis de descarte dos resíduos. Por exemplo, a utilização de material compósito termoplástico permitiria a recuperação direta da fibra e utilização em novas pás eólicas.

Sultan et al. (2018) indicam as seguintes soluções para as pás eólicas pós vida útil: o componente poderia ser vendido em mercados menos maduros; reutilização inovadora, como a transformação de turbinas eólicas desmontadas em playgrounds e centro artísticos infantis como os que podem ser encontrados em vários países europeus como a Holanda e a Dinamarca; reciclagem do material compósito através dos métodos biotecnológicos, químico, eletroquímico, leito fluidizado, fragmentação de alta tensão, reciclagem mecânica e pirólise. Sultan et al. (2018) enfatizam que, antes da reciclagem, as pás eólicas devem ser identificadas, desmontadas e reduzidas em tamanho para facilitar 0 transporte para os centros de processamento e resíduos.

Akbar e Liew (2020) avaliou o potencial da reciclagem de resíduos plásticos reforçados com fibra de carbono na produção de materiais eco eficientes a base de cimento. A fibra de carbono está presente nas indústrias eólicas (pás eólicas), automotiva e aeroespacial. Os autores concluíram que o cimento compósito com $1 \%$ de volume de fibra de carbono reciclada apresentou melhores propriedades mecânicas e menor impacto ambiental em termos de emissão de $\mathrm{CO}_{2}$ quando comparado com o cimento simples e que as fibras recicladas fornecem uma alternativa econômica em relação às fibras de carbono virgem, foi estimado que $70 \%$ do custo pode ser reduzido utilizando $1 \%$ de fibras de carbono reciclada ao invés de fibra de carbono virgem no cimento compósito. Akbar e Liew (2020) ainda ressaltaram ainda que, considerando as turbinas eólicas em fim de vida analisadas no estudo, o setor de energia eólica da China vai chegar a gerar cerca de 75.000 toneladas de desperdício acumulado de polímeros reforçados com fibra de carbono se nenhuma ação proativa for considerada. As fibras de carbono recicladas podem efetivamente ser utilizadas na produção de cimento.

Ratner et al. (2020) indicam que o método mais simples de reciclar um material composto é o mecânico (corte, trituração e amassamento). No entanto, esse método danifica fibras individuas, o que leva à diminuição das características mecânicas. Normalmente, esse material composto reciclado é usado para aplicações menos exigentes: agregados para madeira artificial ou asfalto e concreto na indústria da construção. Os autores citam ainda outros métodos para o processamento de materiais compósitos: pirólise, oxidação em leito fluidizado e decomposição química de resinas poliméricas, 
entretanto, ressalta que todos esses métodos estão ainda em fase de pesquisa de laboratório.

Geiger et al. (2020), corroborando o apontado pelos autores acima, assinala que as principais rotas para os materiais compósitos em fim de vida útil são: aterro, incineração ou reciclagem para a qual a reciclagem tem uma série de abordagens: reciclagem mecânica, térmica ou química sendo, até o momento, uma área imatura. Na percepção dos autores, nenhuma das tecnologias de reciclagem disponíveis atualmente são capazes de atender ao fluxo global de materiais compósitos. Isso significa que as técnicas mencionadas ainda precisam ser otimizadas para produzir material reciclado de maior qualidade e melhorar a eficiência dos recursos. Os autores sugerem a reutilização como a melhor prática: as pás eólicas devem ser reformadas após serem descomissionadas permitindo, assim, estender a vida útil, manter a finalidade original e fazendo pleno uso do design original. Caso não seja possível reutilizar as pás eólicas, os autores recomendam a adaptação para utilização em outros projetos que reaproveitem a forma e as propriedades mecânicas das pás das turbinas eólicas para criar pontes, playgrounds, pontos de ônibus, assentos públicos, placas de sinalização ou garagem para bicicletas.

De modo geral, os artigos avaliados demostraram que as pás das turbinas eólicas são componentes desafiadores para serem reciclados, devido à sua composição. Apesar de existirem métodos para a reciclagem de materiais compósitos, tais como: tecnologias mecânicas, térmicas e químicas, não foi identificado na literatura a evidência de algum parque eólico em que as pás chegaram ao final da vida útil e foram recicladas por algum desses métodos. As principais soluções encontradas para a destinação das pás eólicas foram: envio a aterros, incineração e reutilização em estruturas civis. 0 envio aos aterros não é uma opção ambientalmente adequada, sendo que alguns países europeus (como a Alemanha) já não permitem essa prática. A incineração dos materiais compósitos gera cinzas residuais que são enviadas para os aterros, o que também não caracteriza uma destinação ambientalmente adequada. A reutilização das pás eólicas em projetos estruturais é uma opção para aproveitar o design e as propriedade mecânicas. Desta forma, fica evidente o impacto ambiental associado ao fim da vida útil das pás eólicas e a necessidade urgente de desenvolvimento de novas soluções, que perpassam pelo projeto de pás que visem ao aumento da circularidade do material pós uso e novos processos e produtos para a reciclagem deste material.

Após verificação dos estudos avaliados, pode-se inferir que existem opções para a reciclagem de matérias compósitos. Entretanto, é necessário o avanço dos métodos existentes para uma escala industrial, assim como o desenvolvimento de uma indústria que utilize esses resíduos como matéria-prima em seus processos de produção. Conforme citado pelos autores dos estudos, uma opção é a indústria de cimento ou asfalto para construção civil. Incentivos governamentais poderiam servir de estímulo para essas indústrias. Por fim, vale ressaltar que a reciclagem de materiais compósitos não é um desafio somente da indústria eólica, mas também da indústria automotiva e aeronáutica.

\section{Os desafios para a destinação ambientalmente adequada das pás das turbinas eólicas}

Larsen (2009) aponta que o desafio da reciclagem está no fato da indústria de turbinas eólicas ser relativamente jovem, existir uma quantidade limitada de experiência prática na reciclagem dos componentes das turbinas, particularmente offshore, e que se levará tempo para ganhar experiência prática na desmontagem, separação, reciclagem e descarte dos sistemas de energia eólica. Adicionalmente, o autor sugere que o problema não é o material em si, mas a falta de volume, tornando a reciclagem financeiramente difícil. 0 autor informa ainda que não existe legislação europeia em vigor para a reciclagem de pás de turbinas eólicas e que em outras indústrias - como a automotiva - a responsabilidade fica por conta do fabricante do produto final. Assim, pode-se dizer que o 
fabricante deve desenvolver novas maneiras de produzir pás de turbinas eólicas para fazer o processo de descarte e reciclagem mais factível.

Cherrington et al. (2012) destacam que o principal desafio é o desenvolvimento de um mercado para os materiais reciclados. A reciclagem das pás das turbinas eólicas é inerentemente difícil devido aos seguintes fatores: as pás tem uma composição complexa de fibras, matriz e enchimentos; não podem ser remoldadas devido à natureza das resinas utilizadas; durante os 20 anos de vida útil das turbinas eólicas, as pás são expostas a várias condições hostis: temperaturas extremas, umidade, chuva, granizo, neve, gelo, relâmpago e salinidade, portanto a qualidade reduzida das fibras podem não ser aceitas para a reutilização de componentes estruturais; o tamanho das pás resulta em problemas de logísticas relacionados a desmontagem, transporte e corte.

Em relação aos desafios para o descarte ambientalmente correto das pás eólicas, o estudo de Sultan et al. (2018) caracterizou os parques eólicos existentes no Reino Unido, estimou a quantidade de resíduos de material compósito oriundos das pás eólicas ao final da vida útil e sugeriu um local para o centro de processamento de resíduos que atenderia à rede de logística reversa para, assim, otimizar os custos de logística que foi citado como um desafio para a reciclagem das pás eólicas. Os autores concluíram que, embora os tamanhos das pás das turbinas eólicas tenham aumentado nos últimos anos, não houve modificação significativa na complexidade da separação dos materiais a serem reciclados, sendo o principal desafio a localização do centro de reciclagem.

Ratner et al. (2020) ressaltam que várias tecnologias mecânicas, térmicas e químicas de reciclagem de materiais compósitos utilizados nas pás eólicas estão apenas no início de suas aplicações industriais e que a viabilidade econômica depende não apenas do custo do processo, mas da disponibilidade e do tamanho do mercado de materiais reciclados que pode incluir outras indústrias como a automotivo e a aeronáutica.

Geiger et al. (2020) apontam que os métodos de reciclagem de materiais compósitos existentes atualmente não operam em escala industrial ainda e que diminuem as propriedades mecânicas do material. Desta forma, o descarte dos resíduos sólidos das pás eólicas é mais barato do que a reciclagem.

Em relação ao desafio da logística citado pelos autores, é possível criar um centro de reciclagem das pás eólicas na Bahia utilizando o método gravitacional utilizado por Sultan et al. (2018). Neste método, a localização do centro de reciclagem é definida posição estratégica em relação à localização dos distintos parques eólicos existentes, considerando a quantidade de resíduos compostos gerados por cada parque. Para reduzir os custos de transporte, deve-se pensar na opção de desmontar as pás eólicas e reduzir a um tamanho que permita o transporte em equipamentos "standard" até o centro de reciclagem.

0 estado baiano abriga o Parque Tecnológico da Bahia e outros centros tecnológicos com doutores, mestres e outros estudiosos que desenvolvem pesquisas na área de materiais. Acredita-se que esses profissionais estão capacitados para avaliar a melhor forma de tornar os métodos de reciclagem de materiais compósitos existentes atualmente em escala industrial. 0 estado baiano apresenta a facilidade de contar com alguns fabricantes de pás eólicas no seu território. Através de uma parceria junto com a Fundação de Amparo à Pesquisa do Estado da Bahia (FAPESB), sugere-se abrir um edital nesta linha de pesquisa e, junto com os fabricantes das pás eólicas, desenvolver métodos de reciclagem que seja tecnicamente viável, rentável, escalonável e que permita aproveitar as propriedades mecânicas dos materiais compósitos reciclados.

\section{Discussão}

\section{Políticas públicas para a destinação de resíduos no Brasil e na Bahia}

A Lei no 12.305/2010, que instituiu Política Nacional de Resíduos Sólidos da Bahia (PNRS) (Brasil, 2010), indica que os fabricantes, importadores, distribuidores e 
comerciantes têm a responsabilidade compartilhada de investimento no desenvolvimento, na fabricação e na colocação no mercado de produtos que sejam aptos, após a utilização pelo consumidor, à reutilização, à reciclagem ou a outra forma de destinação ambientalmente adequada.

A Política Estadual de Resíduos Sólidos da Bahia (PERS/BA) foi instituída por meio da Lei no 12.932/2014 (Bahia, 2014). A PERS/BA está em consonância com a PNRS e, dentre os diversos aspectos abordados, destacam-se: a responsabilidade compartilhada pelo ciclo de vida dos produtos, a logística reversa, a produção e o consumo sustentáveis e a valorização dos resíduos sólidos como um bem econômico e social.

Uma pesquisa em linha realizada no Banco de Dados da Assembleia Legislativa da Bahia (ALBA) permitiu identificar um total de oito Projetos de Lei (PL) relacionados à energia eólica. Todos os projetos se referem a políticas de incentivo à implementação deste tipo de obtenção energia no Estado da Bahia. Entretanto, não foi identificada nenhuma lei ou projeto de lei que tratasse da disposição final dos componentes dos parques eólicos, após o final da vida útil.

Em relação à logística reversa, o art. 33, da PNRS (Brasil, 2010), e o art. 53, da PERS/BA (Bahia, 2014) manifestam que os fabricantes, importadores, distribuidores e comerciantes são obrigados a realizar a logística reversa de determinados produtos. Entretanto, nem as pás eólicas e nem os matérias compósitos (que fazem parte da composição das pás eólicas) são citados.

Apesar da Bahia priorizar o crescimento da geração de energia renovável eólica no estado, não foi identificada uma regulamentação que trate da gestão dos resíduos dos componentes dos parques eólicos após o final da vida útil.

Duarte Júnior et al. (2021), em seu estudo a respeito das políticas públicas do setor energético renovável no Estado da Paraíba, evidenciou que a legislação nacional consta termos genéricos e que as regulamentações estaduais avaliadas pelos autores estão associadas aos estímulos fiscais e tributários, apresentando inconsistências a respeito de normativas de incentivo à pesquisa e implementação de tecnologias visando geração de energia renovável. Entretanto, os autores não mencionaram a questão dos resíduos após final de vida útil das tecnologias implementadas, o que reforça a necessidade de haver maior debate sobre esta temática.

\section{Bahia}

\section{Opções e desafios para a destinação correta das pás das turbinas eólicas na}

A seguir, tem-se uma avaliação das opções e desafios para a destinação ou disposição das pás das turbinas eólicas no Estado da Bahia, considerando as opções aterros industriais, incineração, reaproveitamento e reciclagem.

Aterros industriais. A pesquisa permitiu evidenciar que existe a opção de envio das pás eólicas para aterros industriais na Bahia, após o final da vida útil. Foram identificados três aterros industriais localizados na Bahia: Hera Ambiental S/A em São Francisco do Conde, CTR Bahia em São Sebastião do Passé e Mix Soluções Industriais em Lauro de Freitas.

Em relação aos desafios, é necessário avaliar os custos cobrados pelos aterros industriais para realizar a disposição final do resíduo, assim como o tratamento prévio requeridos para os resíduos: estabilização, solidificação, encapsulamento ou neutralização antes de ser enviado para o aterro industrial. Além disso, deve ser avaliado o custo do transporte das pás eólicas até os aterros industriais: o total de 171 pás eólicas com 0 comprimento de $40 \mathrm{~m}$ é caracterizado como transporte especial pela Resolução DNIT no 1/2020 (Brasil, 2020), requerendo, assim, a utilização de equipamentos rodoviários especiais, escolta e a realização do transporte em horário específico, conforme as características da via. 
De forma geral, a disposição das pás em aterros é cara devido às dimensões e o peso e não aproveita o potencial do material composto após a utilização nos parques eólicos.

Incineração. A CETREL é uma empresa brasileira localizada no Pólo Industrial de Camaçari e oferece diversos serviços para as indústrias da região. A empresa tem expertise acumulada no gerenciamento de resíduos sólidos, do recebimento à disposição final.

A CETREL está localizada a uma distância em torno de $600 \mathrm{~km}$ do Parque Eólico de Brotas de Macaúbas.

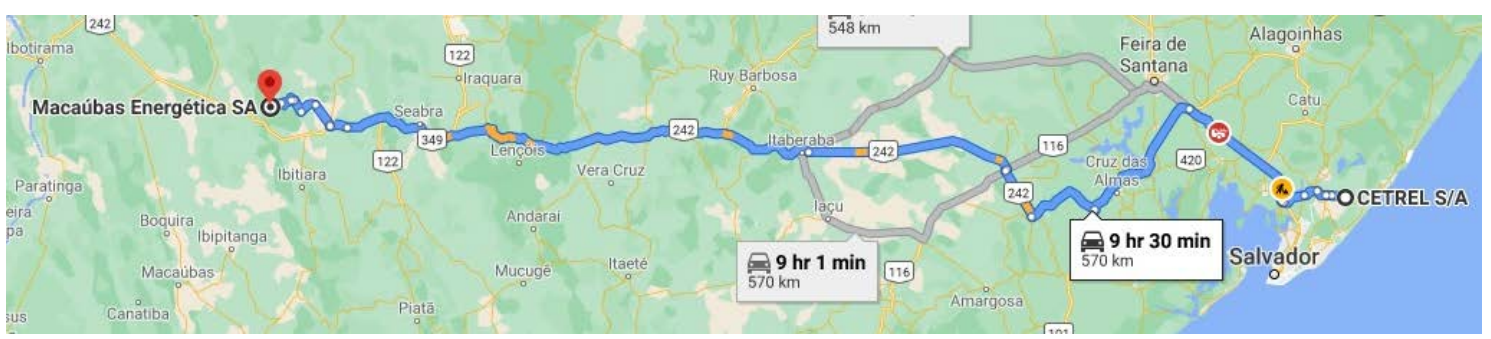

Figura 2. Distância entre o Parque Eólico de Brotas de Macaúbas e a CETREL. Fonte: Google Maps.

De acordo com Albers et al. (2009), uma limitação técnica para a incineração das pás junto a outros materiais é a necessidade de reduzi-las ao comprimento de um metro ou até menos. Desta forma, existe o custo de redução das pás eólicas antes de colocação nos incineradores que deve ser considerado, podendo ser realizado após a desmontagem das pás nos Parques Eólicos e assim otimizar o custo de transporte.

Larsen (2009) ressalta que 60\% do resíduo se torna cinza após o procedimento. Tal cinza pode ser poluente e sua disposição pode ser feita em aterros. Durante a incineração, são emanados gases no processo, que podem gerar impactos ambientais caso não tratados. Os poluentes lançados na atmosfera como decorrência da incineração podem causar doenças respiratórias e problemas reprodutivos à vida humana.

A opção de incineração das pás eólicas existe na Bahia. Entretanto, é necessário realizar uma avaliação detalhada da viabilidade econômica assim como verificar os impactos ambientais dessa solução. A princípio acredita-se que este custo pode inviabilizar esta opção para tratar os resíduos das pás eólicas, e, além disso questiona-se sobre quem irá assumir este custo ou como o mesmo será dividido entre os entes potencialmente responsáveis pelo resíduo.

Reciclagem. Das técnicas de reciclagem apresentadas na Tabela 1, não foi identificado na Bahia nenhuma empresa que realize a reciclagem de materiais compósitos utilizando o processo de pirólise, oxidação em leitos fluidizados e reciclagem química em escala industrial. Foram encontrados somente estudos acadêmicos que avaliam as propriedades mecânicas utilizando esses métodos.

Em relação à reciclagem mecânica, foi identificado que a empresa REVIDA, localizada em Camaçari, possui maquinários para a reciclagem de vidros e pode ser uma opção para a reciclagem das pás eólicas fabricadas na Bahia (as pás eólicas podem ser fabricadas em fibras de vidro ou de carbono). 0 foco da empresa REVIDA é a destinação ambientalmente adequada para resíduos de vidros no Estado da Bahia. A REVIDA é a única empresa de reciclagem de vidro e produção de microesferas da Bahia. 
Os desafios para a trituração das pás das turbinas eólicas são: transporte do local de descomissionamento até o local da reciclagem, redução das pás antes de serem inseridas nos moinhos de trituração, isolamento do local onde será realizado a trituração, pois a formação de pó combinada com finas partículas ou a liberação de gases dos solventes residuais pode afetar a saúde e segurança dos trabalhadores.

Conforme informado no website da empresa, após a trituração e outros processos mecânicos, são produzidos novos materiais para uso na indústria e construção civil, permitindo assim, desenvolver o ciclo fechado da utilização do material compósito

O Município de Camaçari, local onde está instalada a fábrica da REVIDA, possui um Pólo Industrial que conta com indústrias que poderiam utilizar o material compósito triturado oriundo das pás das turbinas eólicas como matéria-prima para os seus produtos, por exemplo a fábrica da Votorantim Cimentos, que abastece os mercados da Bahia, Sergipe e Alagoas, a Sailer Fibras de Vidro, a Fortlev Nordeste, a Polimix Concreto, a Redimix Concreto e a PAVBAHIA Tecnologia em Asfalto.

Reutilização. Existe a possibilidade de desmontagem do aerogerador para reutilização em outro site. Este procedimento envolve uma inspeção de todas as partes antes da remoção das pás, nacele, torres e os sistemas de controle do parque. Adicionalmente, é necessário a montagem de estruturas de sustentação, uma equipe com mão de obra multidisciplinar (eletromecânica, instrumentação e controle etc.), guindastes de movimentação de cargas e toda uma e logística associada à desmontagem eletromecânica. Após a retirada dos equipamentos todos os componentes deverão ser acondicionados adequadamente e preservados (EPE, 2021).

Caso a opção seja reutilização para playground, foram identificadas duas empresas na Bahia que fabricam em escala brinquedos infantis para playground: Lúdico Brinquedos Inteligentes e Sicupira Eucalipto Tratado. Ambas empresas estão localizadas no município de Lauro de Freitas e utilizam como matéria prima principal o eucalipto. Os principais clientes são as prefeituras e condomínios residências do estado. Um exemplo de uso dos resíduos das pás das turbinas eólicas é o playground Wikado, que foi construído na Holanda (Medici 2011). Essa opção pode ser utilizada em municípios da Bahia.

A opção de reutilização das pás eólicas em projetos estruturais para aproveitar o design e as propriedade mecânicas é uma opção possível na Bahia. Uma vez que os grandes consumidores são as prefeituras, o direcionamento do governo estadual poderia tornar essa opção uma realidade. Outras utilizações para bens públicos: construção de pontos de ônibus, abrigos para a chuva, estruturas para armazenamento de bicicletas, entre outros. Entretanto, após a desmontagem, as pás devem ser avaliadas tecnicamente para verificar se os danos causados durante a vida útil (fadiga e falhas mecânicas) podem impactar na nova utilização de forma segura.

A reutilização das pás eólicas em outros projetos estruturais para aproveitar o design e as propriedade mecânicas na Bahia, apesar de ser ambientalmente adequado, são projetos individuais com resultados específicos, assim esse tipo de projeto pode não ser a solução ideal para lidar com o fluxo total de resíduos compostos. Ao verificar a quantidade de pás eólicas que serão descomissionadas nos próximos 15 anos na Bahia, se pode inferir que a necessidade de playgrounds, por exemplo, é muito menor do que a quantidade de pás chegando ao final de sua vida útil.

\section{Conclusão}

Após a avaliação dos estudos, é possível concluir que a destinação das pás utilizadas nas turbinas dos parques eólicos é um problema que afeta todos os países que possuem este tipo de geração de energia. 0 descarte em aterros ou incineração em plantas 
de processamento de resíduos têm sido o tratamento mais comum para as pás eólicas das turbinas eólicas após o final da vida útil no mundo.

0 estudo permitiu identificar opções para a reciclagem das pás eólicas. Entretanto, não foi encontrado na literatura nenhum parque eólico em que as pás das turbinas tivessem passado por um desses processos de reciclagem. Foi identificado que a indústria de reciclagem de materiais compósitos é relativamente jovem e que ainda está em fase embrionária a nível mundial.

Na Bahia, foram identificadas as opções de envio das pás das turbinas eólicas para aterros industriais certificados, para o processo de incineração, reciclagem mecânica e reutilização. Entretanto, deve-se avaliar os custos inerentes: desmontagem, transporte e o custo do descarte e processamento, de acordo com essas opções.

Cabe salientar que a composição da pá da turbina eólica possui matérias valiosos, com propriedades mecânicas que as tornam passíveis de aproveitamento e que merecem um destino mais nobre ao final do seu uso, constando aí o desafio de como recuperá-lo tecnicamente e economicamente. Além disso, outras opções de reciclagem precisam ser desenvolvidas em escala industrial para que permitam utilizar essas características. A Bahia apresenta centros tecnológicos de estudos de materiais, Fundação de Amparo à Pesquisa (FAPESB) e a presença de empresas eólicas no estado, fatores relevantes para o desenvolvimento de um centro de reciclagem de materiais compósitos. Este centro poderia atender, não somente aos parques eólicos localizados na Bahia, mas o Brasil como um todo.

No Brasil e na Bahia, não foi identificada uma lei ou projeto de lei que defina a responsabilidade da desmontagem e descarte final dos componentes dos parques eólicos após a vida útil ou que obrigue os produtores das pás eólicas a construir produtos que sejam recicláveis e que permitam a reinserção no processo produtivo após o final da vida útil. A inclusão das pás eólicas como potencial insumo para fabricação de produtos deve obrigatoriamente passar por logística reversa, através da Lei no 12.305/2010 (Brasil, 2010) e da Lei no 12.932/2014 (Bahia, 2014), porém é preciso estimular os fabricantes, importadores, distribuidores e comerciantes, além do governo, das pás eólicas a buscar uma solução para tornar o material mais fácil de ser reciclável.

Da mesma forma que o governo da Bahia criou leis para incentivar a implantação de empresas de energia eólica e o crescimento da geração através desta fonte no estado, este deve incentivar outras empresas que utilizem os resíduos das pás eólicas como matéria-prima dos seus processos, como a indústria de cimento ou asfalto e, desta forma, desenvolver o conceito de economia circular. Vale ressaltar que as pás eólicas instaladas na Bahia chegarão ao final da vida útil a partir de 2032 e ações precisam ser tomadas definindo as responsabilidades em relação ao descarte final dos componentes eólicos.

Estudos futuros poderiam utilizar o método gravitacional para identificar o local ideal para a instalação de um centro de reciclagem de materiais compósitos no estado baiano que beneficiaria não somente a indústria eólicas, mas outras indústrias como a automotiva e a aeronáutica. Outra opção é realizar o estudo da viabilidade econômica das opções apresentadas neste estudo.

\section{Conflito de interesses}

Os autores declaram não haver conflito de interesses.

\section{Referências}

ABEEÓLICA - Associação Brasileira de Energia Eólica. Boletim Anual de Geração Eólica. ABEEÓLICA, 2020. Disponível em: <http://abeeolica.org.br/dados-abeeolica/>. Acesso em: 17 nov. 2020. 
Akbar, A.; Liew, K. M. Assessing recycling potential of carbon fiber reinforced plastic waste in production of eco-efficient cement-based materials. Journal of Cleaner Production, v. 274, 123001, 2020. https://doi.org/10.1016/j.jclepro.2020.123001

Albers, H.; Greiner, S.; Seifertand, H.; Kühne, U. Recycling of wind turbine rotor blades: Fact or fiction? DEWI Magazin, v.34, p. 32-38, 2009.

Bahia. Lei no 12.932, de 8 de janeiro de 2014. Institui a Política Estadual de Resíduos Sólidos, e dá outras providências. Disponível em: <https://www.legisweb.com.br/ legislacao/?id=264190>. Acesso em: 19 de nov. 2020.

Brasil. Lei no 12.305, de 2 de agosto de 2010. Institui a Política Nacional de Resíduos Sólidos; altera a Lei no 9.605, de 12 de fevereiro de 1998; e dá outras providências. Disponível em: <http://www.planalto.gov.br/ccivil_03/_ato2007-2010/2010/lei/ 112305.htm>. Acesso em: 20 nov. 2020.

Brasil. Resolução DNIT no 1, de 06 de janeiro de 2020. Regulamenta o uso de rodovias federais por veículos ou combinações de veículos e equipamentos, destinados ao transporte de cargas indivisíveis e excedentes em peso ou dimensões ao limite estabelecido nas legislações vigentes, para o conjunto de veículo e carga transportada, assim como por veículos especiais, fundamentado nos art. 21 e 101 da Lei no 9.503, de 23 de setembro de 1997, conhecido como Código de Trânsito Brasileiro - CTB e dá outras providências. Disponível em: <https://www.in.gov.br/web/dou/-/resolucao-n-1-de-6-dejaneiro-de-2020-237206893>. Acesso em: 23 nov. 2020.

Camargo-Schubert. Atlas eólico Bahia. 1. ed. Curitiba: Camargo Schubert Engenheiros Associados, 2013. Disponível em: <http://www.cresesb.cepel.br/publicacoes/ download/atlas_eolico/atlaseolicobahia2013.pdf>. Acesso em: 23 nov. 2020.

Cherrington, R.; Goodship, V.; Mederith, J.; Wood, B. M.; Coles, S. R.; Vuillame, A.; FeitoBoirac, A.; Spee, F.; Kirwan, K. Producer responsibility: Defining the incentive for recycling composite wind turbine blades in Europe. Energy Policy, v. 47, p. 13-21, 2012. https://doi.org/10.1016/j.enpol.2012.03.076

CNI - Confederação Nacional das Indústrias. Energias renováveis na Bahia. São Paulo: CNI, 2016. Disponível em: <http://www.fieb.org.br/midia/2017/6/ESTUDOSETORIALCIN ENERGIASRENOVAVEIS.PDF>. Acesso em: 18 nov. 2020.

Duarte Júnior, E. A.; Menezes, R. A.; Gonçalves, C. S.; Andrade, E. R. Políticas públicas do setor energético renovável no Estado da Paraíba (Nordeste do Brasil): limitações legislativas, entraves técnicos e perspectivas regulamentares. Revista Brasileira de Gestão Ambiental e Sustentabilidade, v. 8, n. 18, p.107-119, 2021. https://doi.org/10.21438/rbgas(2021)081806

EPE - Empresa de Pesquisa Energética. Balanço Energético Nacional 2020, ano base 2019. Rio de Janeiro: EPE, 2020. Disponível em: <https://www.epe.gov.br/pt/ publicacoes-dados-abertos/publicacoes/balanco-energetico-nacional-2020>. Acesso em: 18 nov. 2020.

EPE - Empresa de Pesquisa Energética. Empreendimentos eólicos ao fim da vida útil: situação atual e alternativas futuras. Rio de Janeiro: EPE, 2021. Disponível em: <https://www.epe.gov.br/sites-pt/publicacoes-dados-abertos/publicacoes/Publicacoes Arquivos/publicacao-563/NT-EPE-DEE-012-2021.pdf>. Acesso em: 25 jul. 2021. 
Geiger, R.; Hannan, Y.; Travia, W.; Naboni, R.; Schlette, C. Composite wind turbine blade recycling: Value creation through Industry 4.0 to enable circularity in repurposing of composites. IOP Conference Series: Materials Science and Engineering, v. 942, 012016, 2020. http://doi.org/10.1088/1757-899X/942/1/012016

GWEC - Global Wind Energy Council. Global Wind Report 2020. Brussels: GWEC, 2020. Disponível em: <https://gwec.net/global-offshore-wind-report-2020/>. Acesso em: 18 nov. 2020.

IRENA - International Renewabe Energy Agency. Wind power technology brief. Abu Dhabi: IRENA, 2016. Disponível em: <http://www.irena.org/Publications>. Acesso em: 17 nov. 2020.

Larsen, K. Recycling wind turbine blades. Renewable Energy Focus, v. 9, n. 7, p. 70-73, 2009. https://doi.org/10.1016/S0034-3617(09)70043-8

Liu, P.; Barlow, C. Y. Wind turbine blade waste in 2050. Waste Management, v. 62, p. 229240, 2017. https://doi.org/10.1016/j.wasman.2017.02.007

Medici, Ir. P. Human health risk assessment of "Wikado" playground. 2011. Disponível em: <http://www.woodguide.org/files/2014/09/Human-Health-Risk-Assessment-

Wikado.pdf>. Acesso em: 10 jan. 2021.

Ratner, S.; Gomonov, K.; Revinova, S.; Lazanyuk, I. Eco-design of energy production systems: The problem of renewable energy capacity recycling. Applied Sciences, v. 10, n. 12, p. 4339, 2020. https://doi.org/10.3390/app10124339

SDE - Secretaria de Desenvolvimento Econômico do Estado da Bahia. Informe executivo de eólica. Salvador: SDE, 2020. Disponível em: <http://www.sde.ba.gov.br/index.php/ category/publicacoes-tecnicas/>. Acesso em: 18 nov. 2020.

Sultan, A. A. M.; Mativenga, P. T.; Lou, E. Managing supply chain complexity: Foresight for wind turbine composite waste. Procedia CIRP, v. 69, p.938-943, 2018. https://doi.org/10.1016/j.procir.2017.11.027

Informação da Licença: Este é um artigo Open Access distribuído sob os termos da Licença Creative Commons Attribution, que permite uso irrestrito, distribuição e reprodução em qualquer meio, desde que a obra original seja devidamente citada. 